\title{
Rare Institutional Disruptions and Uphill Capital Flows
}

\author{
Lance Kent \\ College of William and Mary
}

College of William and Mary

Department of Economics

Working Paper Number 146

This Version: November 2013 
COLLEGE OF WILLIAM AND MARY

DEPARTMENT OF ECONOMICS

WORKING PAPER \# 146

November 2013

\title{
Rare Institutional Disruptions and Uphill Capital Flows
}

\begin{abstract}
The puzzle of "uphill capital flows," where capital flows out of countries with relatively lower capital stocks and faster-growing TFP, has reattained prominence in the two decades preceding the recent financial crisis in the form of a large and persistent United States trade deficit with the rest of the world. Asymmetric investment risk has been shown in other studies to be a significant driver of capital flows between countries; how large does the risk have to be to drive capital uphill? This paper builds a model with two large open economies to assess the strength of asymmetric risk as an "uphill" force against the neoclassical "downhill" forces. I assess the model calibrating the foreign country as China, since its "downhill" forces are quite strong. The model shows that if risk arises from only the estimated Gaussian noise of TFP, relatively high coefficients of risk aversion are needed to rationalize the large and steadily growing holdings by foreigners of US assets over the decades preceding the crisis. However, TFP in middleincome countries is subject to other shocks besides Gaussian noise. Recent studies have documented the probability and magnitude of drops in output attributable to rare disruptions to political institutions. This paper shows that this additional risk, even at moderate levels of risk aversion, is enough to drive Foreign investors to engage in decades-long flows of precautionary savings into the United States and quantitatively dominate the effect of Foreign TFP catchup.
\end{abstract}

Keywords: Capital Flows; Portfolio Choice; Rare Disasters; Precautionary Saving.

\author{
Lance Kent \\ College of William and Mary \\ Department of Economics \\ P.O. Box 8795 \\ Williamsburg, VA 23185 \\ United States \\ lckent@wm.edu
}




\section{Introduction}

In the two decades preceding the recent financial crisis, the United States had run a large and persistent trade deficit with the rest of the world. In 2010, the United States' total trade deficit in goods and services was $4.4 \%$ of GDP. The mirror image of this imbalance in goods flows is an inflow of capital into the United States, largely in the form of Treasury bills. Total Treasury debt held by foreigners has increased sharply in the past ten years, from $10 \%$ of GDP to over 30\%. Surprising in light of these facts, a large share of these flows are from countries with relatively low capital stocks and rapidly growing TFP. As established by Lucas (1990), the standard neoclassical growth model predicts that capital should have been flowing to these countries. Gourinchas and Jeanne (2007) call this the "allocation puzzle."

At the same time, rare disasters have been shown to resolve several puzzles in international macro and asset markets 1 . This is especially relevant for countries that are subject to potential political disruptions. Kent and Phan (2013) show that not only are revolutions rare and lead to sharp declines in output and investment when they happen, but the timevarying probability of revolution can itself influence business cycles and entail substantial propagation of shocks. What role can rare disasters play in the resolution of the allocation puzzle?

This paper assesses the quantitative strength of a mechanism in which the potential of a rare disaster in TFP causes prolonged capital flows from growing countries to rich ones. I assess the model using calibrations that give predictions for the bilateral relationship between the US and China. China is not the only country to fit the pattern of low capital stock, fast TFP growth and current account surplus, but it is by far the largest. Roughly half of the total trade deficit of the US in 2007 was attributable to China ${ }^{2}$, while the Chinese share of foreign-held debt as increased from $6 \%$ to $26 \%$. Additionally, China's political and social system are in the middle of a period of dramatic transformation. There is still a non-negligible chance that this transformation will be disrupted ${ }^{3}$. Even if in China's specific case other complementary policy mechanisms have influenced capital flows, reproducing the size and persistence of China's flows presents a high hurdle for any story of aggregate risk. For these reasons, while this paper focuses quantitatively on the relationship between the US and a generic Foreign country, the parametrization of Foreign is chosen to demonstrate the strength of the rare disaster even in a case as stark as China's.

\footnotetext{
${ }^{1}$ For example, Gabaix (2012) and Gourio (2009).

${ }^{2}$ FRED Federal Reserve Bank of St. Louis (accessed July 1, 2011) series IMPCH, EXPCH, and BOPGSTB, sum of monthly values in 2007

${ }^{3}$ See Lewis and Litai (2003) for a discussion of the uncertainty surrounding the outcomes of political and economic reform.
} 
The counterfactual flows predicted by the neoclassical growth model arise from two forces, which I will call the Lucas forces in reference to (Lucas 1990). The first force follows from the fact that China's capital stock was low when it emerged from autarky 4 , I will refer to this force as the Lucas capital stock force. The second force follows from the fact that Chinese TFP has been growing faster than US TFP by about $2 \%$ per year. I will refer to this force as the Lucas TFP growth force. I show that under a reasonable calibration and using these estimated facts about China as a benchmark for the model's Foreign country, the Lucas forces together entail prolonged flows of capital into Foreign. I then argue that greater aggregate risk in Foreign provides a countervailing force quantitatively strong enough to overcome the Lucas forces. The risk arises from two factors. First, I estimate that shocks to TFP are about 3 times more volatile in China. Second, I model the social and political disruption as a rare disaster that takes the form of drop in the level of Foreign TFP. In principle, the net effects of aggregate risk work against the Lucas forces, driving investors to engage in precautionary savings into the United States. In fact, this is the case quantitatively. Up to an adjustment in the initial period, my model can account for the quantitative and qualitative flows of Foreign (here, Chinese) lending to the US since 1992.

My model consists of two large open real economies. They differ only in their stochastic processes for TFP, their initial capital stocks and initial TFP levels. A continuum of agents live in each country. They consume, labor, and split their assets between capital projects at home and an internationally traded non-state-contingent zero net supply bond. Financial markets are incomplete; the bond is the only way capital can flow between countries. There are no nominal rigidities. Agents have Epstein-Zin preferences. A virtue of these preferences is that they disentangle risk aversion from intertemporal elasticity of substitution. In each country, competitive firms produce an internationally traded homogenous good from domestically-sourced capital and labor.

From previous studies, we know the magnitudes of the effects of risk on capital flows when the two countries are symmetric with respect to TFP and capital stock levels. The net effects become nontrivial when there are three competing forces. This paper discusses the transition dynamics that arise from these three distinct forces, and how these effects vary with parameters. To quantify the effects of the Lucas capital stock force, the Lucas TFP growth force and precautionary saving I consider a set of experiments. In each experiment I trace the dynamics of cross-border lending and trade deficits from an initial condition where Foreign emerges from autarky.

No randomness; Lucas capital stock force only In this experiment, Foreign's capital

\footnotetext{
${ }^{4}$ I take this year to be 1992, the year Deng Xiaoping made his Southern Tour and accelerated the market reforms within China. This is the same starting point that Song, Storesletten and Zilibotti (2011) consider.
} 
stock is low but its TFP is at the world frontier. In the first period after autarky is lifted, capital flows from the US to Foreign until the expected marginal products of capital are equal. So, in this period, the US runs a trade surplus. Eventually, the net holding of bonds returns to zero. It follows that the stock of lending from the US to Foreign decreases over time. This amounts to a capital flow from Foreign to the US and a US trade deficit that starts above $20 \%$ of GDP and decays over time. The flows in the first period are the opposite direction of the flows in all following periods.

No randomness; Lucas TFP growth force only In this experiment, Foreign's TFP is low but its capital stock is equal to the US's. In the first period after autarky is lifted, capital flows from Foreign to the US until the marginal products of capital in the two countries are equal. In this instant, the US runs a trade deficit with Foreign. Thereafter, because Foreign TFP grows up to the world frontier, the flows reverse. Capital flows back to Foreign over time, leading to a US trade surplus that starts above $20 \%$ of GDP and slowly decays. This experiment shows that the Lucas TFP growth force entails flows that are quantitatively strong and counterfactual.

No randomness; both Lucas forces The combination of the two Lucas forces amounts in a US trade surplus for the first sixteen years after impact and a trade deficit afterwards, with net lending from the US to Foreign increasing from $10 \%$ of US GDP to almost $70 \%$ of US GDP in the same period. The strength of the Lucas forces is an enormous challenge for any model of imbalances to confront.

Randomness; no Lucas forces In this experiment, the US and Foreign start in autarky with the same capital stock and the same TFP level. The only force in effect is the greater desire by Foreign agents for precautionary saving $4^{5}$. Capital flows from Foreign into the US both in the first and following periods. The US runs a trade deficit with Foreign of over $10 \%$ in the first year and above $6 \%$ the following year. This flow diminishes as time goes on. After sixteen years, the flow of Foreign loans into the US is smaller than the loan repayments in the opposite direction, and the US trade deficit turns into a surplus. In steady state, capital flows cease. So in the limit, Foreign investors hold a constant fraction of their wealth as loans in the US. Also, the US runs a stable trade surplus with Foreign equal to their interest payments to Foreign.

Randomness; both Lucas forces In the final experiment, the Lucas capital stock force, the Lucas TFP growth force and precautionary savings are all present. This experiment captures the net effect of these three forces. After a year of surplus, the US trade

\footnotetext{
${ }^{5}$ In the nonstochastic world, opening up from autarky with each country having the same capital stock and same TFP level has no effect on any equilibrium quantity, since at that point the countries are completely symmetric.
} 
balance becomes a deficit and attains $0.5 \%$ of US GDP after sixteen years. US debt grows monotonically from almost nothing to $6 \%$ of US GDP in the same period.

In conclusion, the model with precautionary savings and rare disasters overcomes the strong Lucas forces to explain key quantitative properties of US-China imbalances.

\section{Literature}

There are many models providing theories on why persistent imbalances arise between rich and poor countries. Models with asymmetries in financial frictions or risk are compatible with mine $\underbrace{6}$ Caballero, Fahri and Gourinchas (2008) stress that the US is better able to create and trade claims on future income. In Matsuyama (2004) and Matsuyama (2005), entrepreneurs in two countries face asymmetric collateral constraints; in equilibrium, this translates into a wedge between rates of return on capital in the two countries. Song et al. (2011) develop an insightful model of the structural transformation within China. Capital flows out of China as entrepreneurial firms shut out from bank lending make up an increasing share of the Chinese economy and Chinese savings cannot be absorbed domestically.

Risk of various forms can also yield asymmetric wedges on returns to capital. In both Mendoza, Quadrini and Rios-Rull (2007) and Angeletos and Panousi (2011), entrepreneurs face financial frictions that prevent them from completely diversifying away their idiosyncratic risk. A combination of less severe financial frictions and lower return volatility in the US leads to capital inflows. Like me, Fogli and Perri (2006), Carroll and Jeanne (2009) and Benhima (2013) explore precautionary savings in the face of aggregate risk.

The contribution of this paper relative to both strands of the above literature is that it quantifies the precautionary savings effects of aggregate risk relative to the powerful Lucas forces that work in the opposite direction. On the one hand, many models that focus on financial frictions such as Matsuyama (2004) and Song et al. (2011) abstract from risk entirely. On the other hand, the models that focus on risk such as Mendoza et al. (2007) and Fogli and Perri (2006) analyze imbalances following liberalization from an autarky that is symmetric with respect to capital stocks and TFP levels. As such they do not assess the quantitative implications of their mechanism against the Lucas forces. It remains for future work to estimate the contribution of each of the various mechanisms in the literature towards observed flows imbalances.

Section Two documents the trends in holdings and balances, constructs measures of and

\footnotetext{
${ }^{6}$ Other models in the literature are not. For example, a mechanism centering on American demand for deficit finance results in capital flows imbalances, but implies a high return on American debt. This is counterfactual: the interest rate on Treasuries has been historically low and declining steadily since the 1990s.
} 
estimates a joint exogenous process for TFP for the US and China. Section Three states the model. Section Four discusses some properties of equilibrium, the calibration, and a set of experiments that trace the dynamics of the model from a set of initial conditions that isolate the Lucas effects and precautionary savings. Section Five concludes.

\section{Empirical Context}

\subsection{Trends in Flows and Holdings}

The goal of this paper is to assess the strength of the rare disaster mechanism in the context of the Lucas and allocation puzzles. To do that, I need to establish a benchmark and a goal for calibration. I take China, as it is the starkest example of low capital stock, rapidly growing TFP and large capital outflows. If the rare disaster mechanism can replicate the experience of China even without other policy interventions, then I have demonstrated the potential strength of this mechanism, both in terms of size and persistence. It is important for the calibration exercise to replicate not just the levels, but the dynamic paths over time of the stocks of debt and flows of goods. This is more than just a business cycle correlation; it is a transition path that runs over two decades.

The major trends for my model to replicate are a growing stock of US debt held by China, and the accompanying a widening trade deficit between the US and China. Specifically, Figure 2 shows the US trade deficit with China growing from $0.25 \%$ in 1992 to almost 2\% in 20107 7 . Chinese holdings of Treasury securities have grown from about half a percent of US GDP in 2000 to about $8 \%$ in $2010^{8}$, as shown in Figure 3 . The same Figure shows that bonds are by far the largest component of US-China cross-border holdings: the stock of US foreign direct investment into China is a small fraction the Chinese holdings of Treasuries, and the stock of Chinese foreign direct investment in the US is negligible.

\subsection{Exogenous Processes}

The levels of American aggregate productivity, $\tilde{Z}$, and Chinese aggregate productivity

$\tilde{Z}^{*}$ are both autoregressive processes about the trend of the global technology frontier $\tilde{\Omega}$. The specification is jointly linear in logs:

\footnotetext{
${ }^{7}$ Source: BEA

${ }^{8}$ Source: Treasury
} 


$$
\begin{aligned}
\log \left(\tilde{\Omega}_{t}\right) & =\log \left(\tilde{\Omega}_{0}\right)+m t \\
\left(\log \left(\tilde{Z}_{t}\right)-\log \left(\tilde{\Omega}_{t}\right)\right) & =\rho\left(\log \left(\tilde{Z}_{t-1}\right)-\log \left(\tilde{\Omega}_{t-1}\right)\right)+\sigma \epsilon_{t} \\
\left(\log \left(\tilde{Z}_{t}^{*}\right)-\log \left(\tilde{\Omega}_{t}\right)\right) & =\rho^{*}\left(\log \left(\tilde{Z}_{t-1}^{*}\right)-\log \left(\tilde{\Omega}_{t-1}\right)\right)+\sigma^{*} \epsilon_{t}^{*}
\end{aligned}
$$

The trend $\tilde{\Omega}$ is deterministic and exhibits constant growth, while $\tilde{Z}$ and $\tilde{Z}^{*}$ are hit with independent standard normal shocks $\epsilon_{t}$ and $\epsilon_{t}^{*}$. Both $\rho$ and $\rho^{*}$ are between zero and 1 , so the processes are trend-reverting.

Estimation. I draw from the World Development Indicators from 1980 onwards to estimate productivity as it is specified in the model. I construct measurements of capital stock, using series on gross fixed capital formation and the permanent inventory method under a depreciation of $8 \%$. I take total labor supplied to be the employment rate multiplied by the labor force, also from the WDI. For output I use values in 2005 PPP US dollars. I assume output is Cobb-Douglas in capital and labor with labor-augmenting technology so that in logs, productivity in each country is a Solow residual. Table 1 presents the results of estimating (1)-(3). Details on time series construction and parameter estimation are in the Appendix.

\begin{tabular}{lccc}
\hline Growth rate of global technology frontier & $m$ & 0.0120 \\
Autocorrelation of US productivity around frontier & $\rho$ & 0.5738 \\
Autocorrelation of Chinese productivity around frontier & $\rho^{*}$ & 0.9839 \\
Standard deviation of shocks to US productivity & $\sigma$ & 0.0121 \\
Standard deviation of shocks to Chinese productivity & $\sigma^{*}$ & 0.0290 \\
\hline
\end{tabular}

Figure 1: Estimates for parameters governing the evolution of productivity in both countries

Innovations to Chinese TFP are about 3 times as volatile $\left(s^{*}\right)$ as those to US TFP $(s)$. The world TFP frontier is growing at about $1.2 \%$ per year $(m)$. Chinese TFP is catching up with the world frontier at about $1.6 \%\left(1-\rho^{*}\right)$ per year. Figure 6 shows the observed TFP levels, the global frontier, and a counterfactual series for Chinese productivity that begins at the observed level of Chinese productivity in 1980 and proceeds deterministically under the estimated autoregressive process. This counterfactual shows the average trend in Chinese productivity catchup to the global technology frontier. Figure 7 plots the estimated residuals $\hat{\epsilon}_{t}$ and $\hat{\epsilon}_{t}^{*}$ in the US and Chinese productivity processes. Note the larger variance in the Chinese process. 


\section{Model}

\subsection{Setup}

There are two countries, the US and Foreign. In each country there is a representative household, a competitive country-specific intermediate sector, and a competitive final good sector. I first describe the US; Foreign is symmetric with starred $\left(^{*}\right)$ variables.

Production. In each country, a competitive firm produces a freely traded, homogenous good $Y_{t}$ using capital $K_{t-1}$ and labor $L_{t}$ under a Cobb-Douglas production function. Technology $Z_{t}$ is labor-augmenting:

$$
Y_{t}=K_{t-1}^{\alpha}\left(Z_{t} L_{t}\right)^{1-\alpha}
$$

This firm hires all labor and capital domestically. It takes the rental rate on capital $R_{t}$ and the labor wage $W_{t}$ as given. All factor markets are competitive, and the firm sells its intermediates at home and abroad at price $P_{t}$ which it takes as given. Its problem is to maximize its profits, $P_{t} Y_{t}-\left(R_{t} K_{t-1}+W_{t} L_{t}\right)$, subject to (4), by choosing $K_{t-1}$ and $L_{t}$.

Productivity: Estimated Processes + Rare Disasters. For the purpose of stationarity and to find a stable saddle-path equilibrium, variables are scaled by the world

technology frontier $\tilde{\Omega}$. For example, let the scaled technologies $\left(Z, Z^{*}\right)$ be $\left(\frac{\tilde{Z}}{\tilde{\Omega}}, \frac{\tilde{Z}^{*}}{\tilde{\Omega}}\right)$ Suppose also that Foreign aggregate productivity is subject to rare discrete downward jumps, or disasters in its level and trend. The jumps $j_{t}$ arrive i.i.d. over time with probability $\psi$. When one arrives, the level of Chinese TFP falls by $J$.

$$
\begin{gathered}
\log \left(Z_{t}\right)=\rho \log \left(Z_{t-1}\right)+\sigma \epsilon_{t} \\
\log \left(Z_{t}^{*}\right)=\rho^{*} \log \left(Z_{t-1}^{*}\right)+\sigma^{*} \epsilon_{t}^{*}-j_{t}^{*} \\
j_{t} \sim \begin{cases}0 & \text { with probability } 1-\psi \\
J & \text { with probability } \psi\end{cases}
\end{gathered}
$$

Households. In each country there is a representative household that consumes, labors, invests in domestic production, participates in international bond markets, and manages a stock of capital.

At time $t$, the household chooses consumption $c_{t}$, capital $k_{t}$ and bonds $b_{t}$. The household goes to the international bond market to trade its bonds with foreigners at the previously determined risk-free rate $\tilde{R}_{t-1}$. If $b_{t}>0$, it is lending, and if $b_{t}<0$, it is borrowing. The bond is the only means by which capital can flow internationally and is in zero net 
supply. In addition, there is a financial friction $\varphi_{t}$ in lending so that the effective rate of return to lending, $\tilde{R}_{t}+\varphi_{t}$, depends on the aggregate amount lent 9 . This financial friction is similar to those surveyed in Schmitt-Grohé and Uribe (2003)'s treatment of closing small open economies. The household earns a return $R_{t}-\delta$ net of depreciation on the capital it lends to domestic firms. It cannot lend directly to foreign firms. It supplies one unit of labor inelastically to earn a wage $W_{t}$. Because the economy is scaled by the global productivity trend, the scaled state variables $k_{t}$ and $b_{t}$ both encounter additional effective depreciation of $m$, the growth rate of the global productivity trend. In sum, the household's budget constraint is:

$$
K_{t}+B_{t}=K_{t-1}\left(1+R_{t}-\delta-m\right)+B_{t-1}\left(1+\tilde{R}_{t-1}+\varphi_{t}-m\right)+L_{t} W_{t}-C_{t}
$$

Subject to its budget constraint, the household recursive utility as in as in Epstein and Zin $(1989)^{10}$. The instantaneous payoff is isoelastic with intertemporal elasticity of substitution equal to $1 / \varsigma$, the certainty equivalent function is CRRA with risk aversion coefficient of $\gamma>0$, and the discount factor is $\beta$.

$$
V_{t}=\max _{c_{t}, k_{t}, b_{t}}\left((1-\beta) \frac{c_{t}^{1-\varsigma}}{1-\varsigma}+\beta \frac{\mathrm{E}\left[V_{t+1}^{1-\gamma}\right]^{\frac{1-\varsigma}{1-\gamma}}}{1-\varsigma}\right)^{\frac{1}{1-\varsigma}}
$$

Equilibrium. Equilibrium is a sequence of $\left(Z_{t}, Y_{t}, R_{t}, W_{t}, K_{t}, L_{t}, C_{t}, B_{t}, V_{t}, Z_{t}^{*}\right.$, $\left.Y_{t}^{*}, R_{t}^{*}, W_{t}^{*}, K_{t}^{*}, L_{t}^{*}, C_{t}^{*}, B_{t}^{*}, V_{t}^{*}, \tilde{R}_{t}\right)$ such that, given initial conditions $\left(Z_{0}, K_{0}, B_{0}, Z_{0}^{*}\right.$, $\left.K_{0}^{*}, B_{0}^{*}, \tilde{R}_{0}\right)$, in all periods $t>0$ exogenous processes are given in $(5)$ and (6), firms in both countries maximize profit subject to (4), households maximize (8) subject to (7) and a suitable transversality condition, and the bond is in zero net supply: $B_{t}=-B_{t}^{*}$.

\subsection{Optimal portfolios}

Portfolio issues. The households' choices on asset allocation are central to the functioning of the precautionary savings mechanism. Below are the US household's Euler equation and portfolio optimality condition:

\footnotetext{
${ }^{9}$ Assume the parametrization $\varphi_{t}=-\varphi_{0} B_{t}$.

10 There is an often-used alternative formulation of Epstein-Zin preferences, $V_{t}=\max _{c_{t}, k_{t}, b_{t}} u\left(c_{t}\right)+$ $\beta \mathrm{E}\left[V_{t+1}^{1-\gamma}\right]^{\frac{1}{1-\gamma}}$. As (Swanson 2013) argues, this is just a special case of the class of preferences I use in this paper, the primary difference being that the standard equilibrium conditions are easier to interpret under the alternative specification. Since there is no labor supply choice in my model, I find it relatively straightforward to stay closer to Epstein and Zin (1989)'s original specification.
} 


$$
\begin{aligned}
C_{t}^{-\varsigma} & =\beta\left(E_{t} V_{t+1}^{1-\gamma}\right)^{\frac{\gamma-\varsigma}{1-\gamma}} E_{t}\left[V_{t+1}^{\varsigma-\gamma} C_{t+1}^{-\varsigma}\left(R_{t+1}+1-\delta-m\right)\right] \\
0 & =E_{t}\left[V_{t+1}^{\varsigma-\gamma} C_{t+1}^{-\varsigma}\left(R_{t+1}-\delta-\left(\tilde{R}_{t}+\varphi_{t+1}\right)\right)\right]
\end{aligned}
$$

There's a well-known problem in any model with a Merton (1971)-style portfolio choice with equity in a nonstochastic steady state, the optimal portfolio is either indeterminate or unbounded. The problem arises because the optimal portfolio is a ratio of moments of the return processes, with only second moments in the denominator. Since the second moments vanish at the point of approximation, the excess returns among each pair of assets must vanish as well to avoid explosions. If the excess returns vanish and equity stakes are perfect substitutes across investors, then diminishing returns pins down the total capital invested in each project without pinning down the allocation of individual portfolios between projects. I avoid this problem by restricting asset trade to a single risk-free bond. In the absence of randomness, the expected rates of return on both capital stocks and the bond will be equal up to depreciation and lending financial frictions, and the diminishing returns in production will pin down the capital stock and portfolio allocations in each country.

I approximate the model with randomness about a point where the future values of all exogenous shocks are sent to zero. A perturbation parameter recovers the first two moments of the future shocks; as I expand the equilibrium conditions in the perturbation parameter, higher order terms pick up the curvature of the Epstein-Zin specification and the equilibrium allocation of assets exhibits risk aversion. The perception of risk has two effects: a static one and a dynamic one. In the static effect, risk acts as a wedge between the marginal rates of capital between the two countries. Market clearing for the global zero-net-supply bond provides a single risk-free rate to investors in both countries. Households in Foreign, subject to greater labor income risk, demand this risk-free asset to a greater extent than households in the US do. In the absence of Lucas forces, this drives the risk-free rate to the point where Foreign agents demand debt and US agents supply it. The dynamic effect is driven by the precautionary savings motive. Emerging from autarky, Foreign agents will demand a greater stock of precautionary savings in a stochastic steady state since their labor income carries greater risk. The accumulation of this stock of precautionary savings will take many years, especially if the stock of precautionary savings to be reached in the limit is large. This dynamic motive is what gives rise to the large and persistent flows out of the Foreign country, well beyond the initial period where capital flows to equalize rates of return on

\footnotetext{
${ }^{11}$ See Schmitt-Grohé and Uribe (2003); Benigno and Nisticò (2009); Devereux and Sutherland (2007); Tille and van Wincoop (2008).
} 
capital up to a risk wedge. This dynamic effect is what overpowers the Lucas forces.

\section{Numerical Exploration}

Baseline calibration. The parameters of the model are calibrated to a time-scale in years to conform with the data. The discount rate $\beta$ are standard, and chosen to obtain a risk-free rate of $\frac{1}{\beta}+m$, or about six percent per year. I choose a coefficient of risk aversion $\gamma$ in line with the literature on the equity premium, and a financial friction parameter $\varphi_{0}$ to be relatively small. Karabarbounis and Neiman (2013) estimate the capital share $\alpha$ to be 0.625 in China and 0.375 in the US as of 2005, with recent evidence indicating the capital share is increasing over time. Since I want to highlight the effects of asymmetric risk, I abstract from the effects of asymmetric capital shares and choose an intermediate value of 0.45 for both countries.

It's relatively straightforward to estimate the volatility of a process for TFP. But how likely is it that there will be a political disruption in a country like China? Recent history in East Asia provides several examples: using series from Maddison (2010) on real per capita output in China starting in 1950, one sees that the Great Leap Forward, starting in 1958, led to a $20 \%$ decline in output and the Cultural Revolution, starting in 1966, resulted in a 9.5\% decline. The logarithm of Maddison's series is plotted in figure 4 , with dashed lines indicating the onset of these two events.

One approach to calibrating the disaster process is to exploit the results in Barro (2006). Barro estimated large falls in real per capita output across a panel of countries in the twentieth century. He found that events where output falls greater than $15 \%$ occur with an annual probability of about $1.7 \%$ and entail a median drop in output of $22 \%$. It is reasonable to assume that China is no more stable than the countries in Barro's panel. In one calibration, I assume that drops in Chinese TFP occur with the same probability are of the same size as Barro's rare events. In this calibration I assume an arrival rate $\psi$ that is the same as Barro's, that is, $1.7 \%$ per year and I choose the jump size $J$ to entail a fall in output of $24 \%$, close to the median of Barro's distribution.

But the events in Barro's panel are generally violent, and often interstate conflicts. One of the goals of this paper is to show that the rare disaster approach works not just for truly catastrophic events, but also for milder but still significant disruptions to institutions. After all, the disaster in this paper not a loss of capital, but rather a fall in TFP; while the events in Barro's panel favor the former, an alternative set of events better characterize the latter. The calibration I use to represent institutional disruptions is taken from Kent and Phan (2013). The authors in that paper explore the effects of events taken from a database of 


\begin{tabular}{lcc}
\hline Capital share & $\alpha$ & 0.45 \\
Discount rate & $\beta$ & 0.95 \\
Depreciation rate & $\delta$ & 0.08 \\
Bond return curvature & $\phi_{0}$ & 0.001 \\
Intertemporal elasticity of substitution & $\varsigma$ & 1 \\
Risk aversion coefficient & $\gamma$ & 7.5 \\
Disaster arrival probability & $\psi$ & 0.08 \\
Disaster size (loss in log points of TFP) & $J$ & 0.15 \\
\hline
\end{tabular}

Table 1: Baseline calibration

mass campaigns whose stated intention is to bring about regime change. Not all of these campaigns are successful, and few are violent. The authors document that the probability of entering into a state of unrest associated with one of these campaigns varies according to political institutions and economic conditions, but can be between $5 \%$ and $10 \%$ for a country under a regime that is partially autocratic. These episodes are associated with significant losses of output, namely a decline in output growth by $5 \%$ per year while they occur. To represent this kind of episode in the framework of this project, I assume a calibration where the size of the jump is a loss of TFP that corresponds to an episode that lasts two years: that is, a fall in the level of output by $10 \%$ relative to trend. I also assume that these events arrive with a probability of $8 \%$ per year.

\subsection{Experiments}

Overview. If aggregate risk can overcome the stark Lucas forces for China, then it is certainly strong enough to be quantitatively significant in resolving the allocation puzzle. When China left autarky in the 1980s and 1990s, it differed from the US in that its capital stock was lower, and its TFP level was lower, more volatile, and catching up with the US. In other words, there were three forces at play between the two countries in the years since: the Lucas capital stock force, the Lucas TFP growth force, and the precautionary savings force. To disentangle the effects of each force, this section will conduct a series of experiments for each of several parametrizations of the model. In each experiment, the initial event will be the full emergence of Foreign from autarky, an initial condition to represent China in 1992 following Deng Xiaoping's Southern Tour ${ }^{12}$. The graphs of the dynamics of several key variables appear in the Appendix. Each experiment differs in a) the initial conditions of Foreign capital and TFP relative to the US and b) the nature of randomness in the world.

\footnotetext{
${ }^{12}$ China had been in the process of liberalization since the land reforms of 1978, but Deng Xiaoping's largely symbolic tour gave impetus to accelerated reforms so I choose it as the starting point for the calibration.
} 
For each type of randomness, there are four experiments: In the first, Foreign TFP and capital are equal to those of the US in 1992. This experiment has no Lucas forces. In the second experiment, only the Lucas capital stock force is present: Foreign capital is equal to $15 \%$ of the US, as measured in the data for China, but Foreign TFP is the same as the US. In the third experiment, only the Lucas TFP growth force operates: Foreign TFP is $3 \%$ that of the US as in the data for China but capital is the same as the US. Finally, the fourth experiment will have both Lucas forces: both Foreign capital and TFP are at the low levels measured in the data. I repeat these experiments for a nonstochastic world and several worlds that differ in the nature of aggregate risk faced by Foreign agents.

\subsection{Experiments: Table 2, nonstochastic}

Table 2 shows experiments conducted with all sources of randomness turned off. These graphs display the full effects of the Lucas forces without any countervailing precautionary savings motives.

No Lucas forces. The first row of graphs represent a scenario where the the world leaves autarky from the symmetric nonstochastic steady state. Nothing happens because the US are and Foreign are completely symmetric in this case. There are no imbalances of any kind: both debt and the trade deficit are zero.

Lucas capital stock force only. The second row of Table 2 shows an experiment in which Foreign capital starts low. In the first period after liberalization, the higher marginal product of capital in Foreign pushes up the world risk-free rate, enticing Americans to lend abroad. Enough capital flows instantly to equalize the returns around the world. This initial adjustment is indicated by a spike on the graphs. The Americans hold as much wealth as they did in autarky, but a portion of it is lent abroad and installed as capital overseas. From this point, total world capital (which is equal to total world wealth) begins to grow up to its steady state value. Initially both Foreign and American wealth grow, which means American wealth is above its initial value. The financial friction plays an important role in what happens from this point on. Suppose there was no financial friction. In the limit as time goes on, total world wealth will attain its steady state value but the distribution of wealth between the two countries will not. The initial advantage that the Americans enjoyed will be permanent as Americans will continue to accumulate wealth over their initial stock until the world return on capital declines to its steady state value. But I'm interested in an equilibrium where not just the total stock of world wealth, but also its distribution has a steady state independent of initial conditions. To achieve this, I assume a financial friction where the return earned on bonds decreases in aggregate lending. After enjoying an increase 
in wealth over their autarky level, Americans will see their wealth decline as the financial friction erodes their earnings on lending abroad. This accounts for the humped shape of US wealth in this experiment.

Because the symmetric steady state shown in the first row will eventually be attained, total lending to Foreign eventually returns to zero from an initially high amount. This amounts to an ongoing reverse flow from Foreign to the US from the second instant on. This ongoing reverse flow has implications for each variable: Foreign agents are saving more than they are investing as fractions of GDP, and the US trade deficit is positive.

Lucas TFP growth force only The third row of Table 2 shows an experiment in which Foreign TFP starts low and grows up to the world frontier. This experiment is the mirror image of the previous one. Emerging from autarky, since the marginal product of capital is much higher in the US, the risk-free rate falls and Foreign agents lend to Americans. Capital flows to the US, but only for the first year. Starting the second instant and continuing for decades, the Lucas TFP growth force drives capital flows in the opposite direction. The US runs a trade surplus with Foreign, and Foreign investment is greater than savings. Eventually, all quantities graphed find their way to the symmetric pre-liberalization steady state.

Both Lucas capital stock force and Lucas TFP growth force Combining the first three experiments yields this one, which is roundly counterfactual. The fact that Foreign initial capital is low means the US lends $10 \%$ of its GDP abroad initially; that Foreign TFP is growing means that lending actually increases over the first twenty-five years, up to over $70 \%$ of US GDP. The US runs a surplus for the first sixteen years, starting at $8 \%$ of GDP. This scenario is completely at odds with the data.

\subsection{Experiments: Table 3, both noise and rare social unrest}

The experiments of Table 3 are from the benchmark calibration. There are two sources of aggregate risk: the observed Gaussian noise and the potential for a disruption to institutions through mass unrest. In this scenario, the counterfactual trends from the nonstochastic world are reversed, bringing the predicted paths of debt and trade deficits into the same vicinity as the observed paths.

No Lucas Forces. These graphs show the dynamic effects of leaving autarky with aggregate risk. No actual disasters occur in these experiments, but the potential that one could happen weighs heavily on agents' decisions. The main effect is captured in the first row, which shows the transition from a symmetric autarky to the new steady state. In this row, the US and China start in autarky with the same capital stock and the same TFP level. The only force in effect is the greater desire by Chinese agents for precautionary savings. The 
threat of disasters in Foreign provokes a large and persistant flow of precautionary savings that takes place over decades. This flow slows as time goes on. After sixteen years, the flow of Chinese loans into the US is smaller than the loan repayments in the opposite direction, and the US trade deficit turns into a surplus. In steady state, capital flows cease. So in the limit, Chinese investors hold a constant fraction of their wealth as loans in the US. Also, the US runs a stable trade surplus with China equal to their interest payments to China.

Both Lucas Forces. The net effect of precautionary savings together with the Lucas Forces is shown in the last row of Table 3. The qualitative contrast between this and the last row in Table 2 is stark. The precautionary savings motive has reversed the flow of capital between the US and Foreign, and while the predicted paths for the trade deficit aren't exactly in line with the data, the gap between prediction and data has closed considerably, to within a percent of US GDP.

\subsection{Experiments: Tables 4 through 7 , alternative calibrations}

In Tables 4 through 7, I consider several alternative calibrations that vary both the nature of risk in Foreign and agents' attitudes towards it.

In Table 4, I consider a parametrization in which there is asymmetry in risk due to the Gaussian noise but there are no disasters. This shrinks the precautionary savings motive; in fact it shrinks it so much that the US lends about 50\% of its GDP to Foreign after sixteen years. This it an improvement (in terms of approaching the data) over the nonstochastic world, which predicts the US to lend almost $70 \%$ of its GDP to Foreign, but nowhere near the uphill capital flow in the data. In other words, while the noise itself is able to close the gap in lending by $20 \%$ of US GDP, the presence of disasters closes it by an additional $60 \%$. Why do the disasters have such a larger effect than the Gaussian noise? Under this calibration, the uncentered second moment of the disaster process is about a little over twice the size of the variance of the Gaussian process estimated for Chinese TFP. In addition, the disaster process implies a first-order effect because the mean of the jump process is nonzero. So, if there are rare disasters of the kind assumed here, the estimated process not only underestimates the variance of the process that investors believe holds in Foreign, it underestimates the mean of the process as well.

The strength of the precautionary savings motive depends on agents' response to risk. The response increases both in the moments of the process for TFP itself and in the risk aversion coefficient that agents hold. Table 5 shows the Lucas and precautionary forces under an alternative parametrization where the coefficient of risk aversion $\gamma$ is set to 5 instead of the baseline 7.5. The random processes themselves are as in the baseline calibration. The 
lower risk aversion entails less precautionary savings; in the end, the gap between predicted stocks of lending and observed stocks of lending is closed by $60 \%$ of US GDP, but this still leaves the US lending up to about 10\% of its GDP to Foreign after 16 years, and a US trade surplus with Foreign until the year 2004.

Using the insight from Table 5, one might ask to what extent the coefficient of risk aversion might substitute for the rare disaster process. Table 6 shows a parametrization where the disaster process is turned off, but the coefficient of risk aversion is set to an unrealistically high value of 25. Even this is not enough to prompt Foreign agents to lend to the US; in 2008 the US is lending about $25 \%$ of its GDP to Foreign.

Table 7 shows a parametrization that replaces the moderate institutional disruptions explored in Kent and Phan (2013) with the rarer but more severe disasters of Barro (2006). The effects on trade deficits and cross-border lending are roughly similar between the two parametrizations. In other words, an increasing size of disasters can substitute for their decreasing frequency.

\section{Conclusion}

This paper presents a model where the portfolio investment decisions of investors at home and abroad drive trade and capital flows imbalances that are quantitatively consistent with a very stark case of "uphill" flows: the United States and China. The model shows that the

potential effect of risk aversion in the face of rare disasters in a Foreign country can inspire so much precautionary savings into the United States that, despite the twin Lucas forces from low Foreign capital and growing Foreign TFP, capital flows on net into the United States. This story is complementary with other stories in the literature, namely ones that suppose idiosyncratic risk and financial frictions outside of the United States. Still, this model shows that aggregate risk can be quantitatively strong enough to explain several key facts on its own. Given that many countries are subject to rare political and institutional disruptions, this mechanism may contribute substantially to the resolution of the "allocation" puzzle and the general understanding of middle-income business cycles and capital flows. 


\section{References}

Andreasen, Martin M, Jesús Fernández-Villaverde, and Juan Rubio-Ramírez (2013) 'The Pruned State-Space System for Non-Linear DSGE Models: Theory and Empirical Applications.' Technical Report, National Bureau of Economic Research

Angeletos, G.M., and V. Panousi (2011) 'Financial integration, entrepreneurial risk and global dynamics.' Journal of Economic Theory

Barro, R.J. (2006) 'Rare disasters and asset markets in the twentieth century.' The Quarterly Journal of Economics 121(3), 823-866

Benhima, Kenza (2013) 'A reappraisal of the allocation puzzle through the portfolio approach.' Journal of International Economics 89(2), 331 - 346

Benigno, P., and S. Nisticò (2009) 'International portfolio allocation under model uncertainty.' Working Paper

Caballero, R.J., E. Fahri, and P.-O. Gourinchas (2008) 'An equilibrium model of global imbalances and low interest rates.' American Economic Review 98(1), 358-393

Carroll, C., and O. Jeanne (2009) 'A tractable model of precautionary reserves or net foreign assets'

Devereux, M.B., and A. Sutherland (2007) 'Country portfolio dynamics'

Devereux, Michael B, and Alan Sutherland (2010) 'Country portfolio dynamics.' Journal of Economic Dynamics and Control 34(7), 1325-1342

Epstein, Larry G, and Stanley E Zin (1989) 'Substitution, risk aversion, and the temporal behavior of consumption and asset returns: A theoretical framework.' Econometrica: Journal of the Econometric Society pp. 937-969

Federal Reserve Bank of St. Louis (accessed July 1, 2011) 'FRED, federal reserve economic data'

Fogli, A., and F. Perri (2006) 'The great moderation and the U.S. external imbalance.' Monetary and Economic Studies 24, 209-224

Gabaix, Xavier (2012) 'Variable rare disasters: An exactly solved framework for ten puzzles in macro-finance.' The Quarterly Journal of Economics 127(2), 645-700

Gourinchas, P.O., and O. Jeanne (2007) 'Capital flows to developing countries: The allocation puzzle'

Gourio, Francois (2009) 'Disasters risk and business cycles.' Technical Report, National Bureau of Economic Research

Judd, K.L. (1998) Numerical Methods in Economics (The MIT press)

Karabarbounis, Loukas, and Brent Neiman (2013) 'The global decline of the labor share.' Technical Report, National Bureau of Economic Research

Kent, L., and T. Phan (2013) 'Business cycles with revolutions'

Kim, J., S. Kim, E. Schaumburg, and C.A. Sims (2008) 'Calculating and using second-order accurate solutions of discrete time dynamic equilibrium models.' Journal of Economic Dynamics and Control 32, 3397-3414 
Lewis, John W., and Xue Litai (2003) 'Social change and political reform in China: Meeting the challenge of success.' The China Quarterly 176, 926-942

Lucas, R.E. (1990) 'Why doesn't capital flow from rich to poor countries?' American Economic Review 80(2), 92-96

Maddison, A. (2010) Statistics on World Population, GDP and Per Capita GDP, 1-2008 AD (University of Groningen)

Matsuyama, K. (2004) 'Financial market globalization, symmetry-breaking, and endogenous inequality of nations.' Econometrica 72(3), 853-884

- (2005) 'Credit market imperfections and patterns of international trade and capital flows.' Journal of the European Economic Association 3(2-3), 714-723

Mendoza, E.G., V. Quadrini, and J.V. Rios-Rull (2007) 'Financial integration, financial deepness and global imbalances'

Merton, R.C. (1971) 'Optimum consumption and portfolio rules in a continuous-time model.' Journal of Economic Theory 3(4), 373-413

Schmitt-Grohé, S., and M. Uribe (2003) 'Closing small open economy models.' Journal of International Economics 61(1), 163-185

Song, Z., K. Storesletten, and F. Zilibotti (2011) 'Growing like China.' American Economic Review 101(1), 196-233

Swanson, Eric T. (2013) 'Risk aversion, risk premia, and the labor margin with generalized recursive preferences'

Tille, C., and E. van Wincoop (2008) 'International capital flows.' Journal of International Economics 80(2), 157-175 


\section{A Appendix}

\section{A.1 Estimation of exogenous processes}

I estimate TFP in the US and China as the residual from the production function $Y_{t}=$ $K_{t-1}^{\alpha}\left(\tilde{Z}_{t} L_{t}\right)^{1-\alpha}$. The labor input $L_{t}$ is the labor force times one minus the unemployment rate. The capital stock $K_{t}$ is constructed using the perpetual inventory method. The first annual observation is 1980 .

$$
\begin{aligned}
g_{0} & =\frac{\log \left(I_{1989}\right)-\log \left(I_{1980}\right)}{9} \\
K_{1980} & =\frac{I_{1980}}{g_{0}+\delta} \\
K_{t} & =(1-\delta) K_{t-1}+I_{t-1} \quad \forall t>1980
\end{aligned}
$$

The measured $\log$ TFP in each country is then $\log \left(\tilde{Z}_{t}\right)=\frac{1}{1-\alpha}\left(\log \left(Y_{t}\right)-\alpha \log \left(K_{t-1}\right)\right)-\log \left(L_{t}\right)$. Using these series, I estimate (2) for the US by regressing $\log \left(\tilde{Z}_{t}\right)$ on $\log \left(\tilde{Z}_{t-1}\right)$, a constant, and $t$. Coefficients reported in the text are transformations of the coefficients in the regression using the following relationship derived from (2):

$$
\log \left(\tilde{Z}_{t}\right)=\log \left(\tilde{\Omega}_{0}\right)(1-\rho)+m(1-\rho) t+\rho \log \left(\tilde{Z}_{t-1}\right)+\sigma \epsilon_{t}
$$

The standard deviation of the fitted residuals $\hat{\epsilon}_{t}$ is an estimate of $\sigma$.

Using $\log \left(\tilde{\Omega}_{0}\right)$ and $m$ I construct the global technology frontier $\tilde{\Omega}_{t}$ and the gap between Chinese TFP and the global frontier $\left(\log \left(\tilde{Z}_{t}\right)-\log \left(\tilde{\Omega}_{t}\right)\right)$. I estimate the Chinese TFP process by regressing $\left(\log \left(\tilde{Z}_{t}\right)-\log \left(\tilde{\Omega}_{t}\right)\right)$ against $\left(\log \left(\tilde{Z}_{t-1}\right)-\log \left(\tilde{\Omega}_{t-1}\right)\right)$ and obtain estimates of $\rho^{*}$ and $\sigma^{*}$.

\section{A.2 Solution via perturbation}

Let $\mathbf{Y}$ be the vector of endogenous variables in the model. Let $\mathbf{e}$ be the vector of Gaussian innovations, and $j$ be the rare disaster shock. Let $\eta$ be the perturbation parameter. Let $\mathbf{F}$ be the equilibrium conditions: $0=E_{t} \mathbf{F}\left(\mathbf{Y}_{t+1}, \mathbf{Y}_{t}, \mathbf{Y}_{t-1}, \mathbf{e}_{t}, j_{t}, \eta\right)$. Let $\mathbf{g}$ be the rational expectations policy function that satisfies the equilibrium conditions $\mathbf{F}: \mathbf{Y}_{t}=\mathbf{g}\left(\mathbf{Y}_{t-1}, \mathbf{e}_{t}, j_{t}, \eta\right)$. In other words, $\mathrm{g}$ is the function implicitly defined by:

$$
0=E_{t} \mathbf{F}\left(\mathbf{g}\left(\mathbf{g}\left(\mathbf{Y}_{t-1}, \mathbf{e}_{t}, j_{t}, \eta\right), \eta \mathbf{e}_{t+1}, \eta j_{t+1}, \eta\right), \mathbf{g}\left(\mathbf{Y}_{t-1}, \mathbf{e}_{t}, j_{t}, \eta\right), \mathbf{Y}_{t-1}, \mathbf{e}_{t}, j_{t}, \eta\right)
$$

Solving the model with the perturbation method ${ }^{13}$ means calculating a Taylor approximation for the policy function $\mathbf{g}\left(\mathbf{Y}_{t-1}, \mathbf{e}_{t}, j_{t}, \eta\right)$ about the point $(\overline{\mathbf{Y}}, 0,0,0)$, the nonstochastic steady state.

\footnotetext{
${ }^{13}$ The best reference is Judd (1998).
} 
The parameter $\eta$ is used to approximate the solution to the model. The model of interest is where $\eta=1$. The solution method approximates the model of interest around a deterministic version where $\eta=0$. At this point, the forward-looking values of both the Gaussian noise and the jumps vanish.

As is common in other international macro models with portfolio choice (e.g. (Devereux and Sutherland 2010)), it is necessary to take the model to at least a second-order approximation to capture the effects of risk on agents' decisions. Let $\overline{\mathbf{X}}=\mathbf{g}(\overline{\mathbf{X}}, 0,0,0), \overline{\mathbf{g}}_{\mathbf{X}}=\mathbf{g}_{\mathbf{X}}(\overline{\mathbf{X}}, 0,0,0)$ and so on. I calculate and report experiments using a policy function that is jointly second order in $\left(\mathbf{X}_{t-1}, \mathbf{e}_{t}, j_{t}, \eta\right)$ but dropping any terms that are jointly second order in $\left(\mathbf{X}_{t-1}, \mathbf{e}_{t}, j_{t}\right){ }^{14}$;

$$
\mathbf{g}\left(\mathbf{X}_{t-1}, \mathbf{e}_{t}, j_{t}, \eta\right) \approx\left(\overline{\mathbf{X}}+\overline{\mathbf{g}}_{\eta}+\frac{1}{2} \overline{\mathbf{g}}_{\eta \eta}\right)+\left(\overline{\mathbf{g}}_{\mathbf{X}}+\overline{\mathbf{g}}_{\mathbf{X} \eta}\right)\left(\mathbf{X}_{t-1}-\overline{\mathbf{X}}\right)+\left(\overline{\mathbf{g}}_{\mathbf{e}}+\overline{\mathbf{g}}_{\mathbf{e} \eta}\right) \mathbf{e}_{t}+\left(\overline{\mathbf{g}}_{j}+\overline{\mathbf{g}}_{j \eta}\right) j_{t}
$$

I calculate an approximation that is only to first order in $\left(\mathbf{X}_{t-1}, \mathbf{e}_{t}, j_{t}\right)$ because I want to avoid explosions 15 . Taking a second order approximation in $\eta$ entails evaluating expectations of $\mathbf{e}_{t+1}$. I do not drop these terms, since after the evaluation of the expectation these terms do not lead to explosive paths.

The second-order approximation in the presence of jumps implies that the standard results for a second-order approximation are somewhat altered. For example, consider the first-order approximation of the equilibrium conditions $F$ in $\eta$ :

$$
0=E_{t}\left[\overline{\mathbf{F}}_{1}\left(\overline{\mathbf{g}}_{Y} \overline{\mathbf{g}}_{\eta}+\overline{\mathbf{g}}_{e} \mathbf{e}_{t+1}+\overline{\mathbf{g}}_{j} j_{t+1}+\overline{\mathbf{g}}_{\eta}\right)+\overline{\mathbf{F}}_{2} \overline{\mathbf{g}}_{\eta}+\overline{\mathbf{F}}_{6}\right]
$$

In the presence of purely Gaussian noise $\mathbf{e}_{t+1}$ (and no direct effects of the perturbation parameter aside from sending the future values of the exogenous shocks to zero, i.e. $F_{6}=0$ ), The term $E_{t} \mathbf{e}_{t+1}$ evaluates to zero and thus $\overline{\mathbf{g}}_{\eta}=0$. However, $E_{t} j_{t+1}=\psi J \neq 0$ and so the perturbation parameter introduces a first-order effect. The second order effects are present as in the case of purely Gaussian noise as well. To the usual effects of $E_{t}\left[\mathbf{e}_{t+1} \mathbf{e}_{t+1}^{\prime}\right]=\operatorname{diag}\left(\left[\sigma, \sigma^{*}\right]\right)$, the jumps add $E_{t}\left[j_{t+1}^{2}\right]=\psi J^{2}$. Thus, an increase in either the probability of the disaster $\psi$ or the disaster loss size $J$ has both a first-order and second-order effect on equilibrium allocations. Since this feature of the model is nonstandard, I do not rely on Dynare or a similar standard package to calculate the required higher order derivatives of $\mathbf{F}$ and $\mathbf{g}$; I perform these calculations with my own code which is available on request.

\footnotetext{
${ }^{14}$ Note that in this expression cross terms such as $\overline{\mathbf{g}}_{\mathbf{X}} \eta$ appears only once. This term represents the sum of the two terms $\frac{1}{2} \overline{\mathbf{g}}_{\mathbf{X} \eta}$ and $\frac{1}{2} \overline{\mathbf{g}}_{\eta \mathbf{X}}$, reshaped conformably for convenience.

${ }^{15}$ For a discussion of how higher-order approximations can explode, see Kim, Kim, Schaumburg and Sims (2008). Andreasen, Fernández-Villaverde and Rubio-Ramírez (2013) provide an alternative approach to avoid explosions.
} 


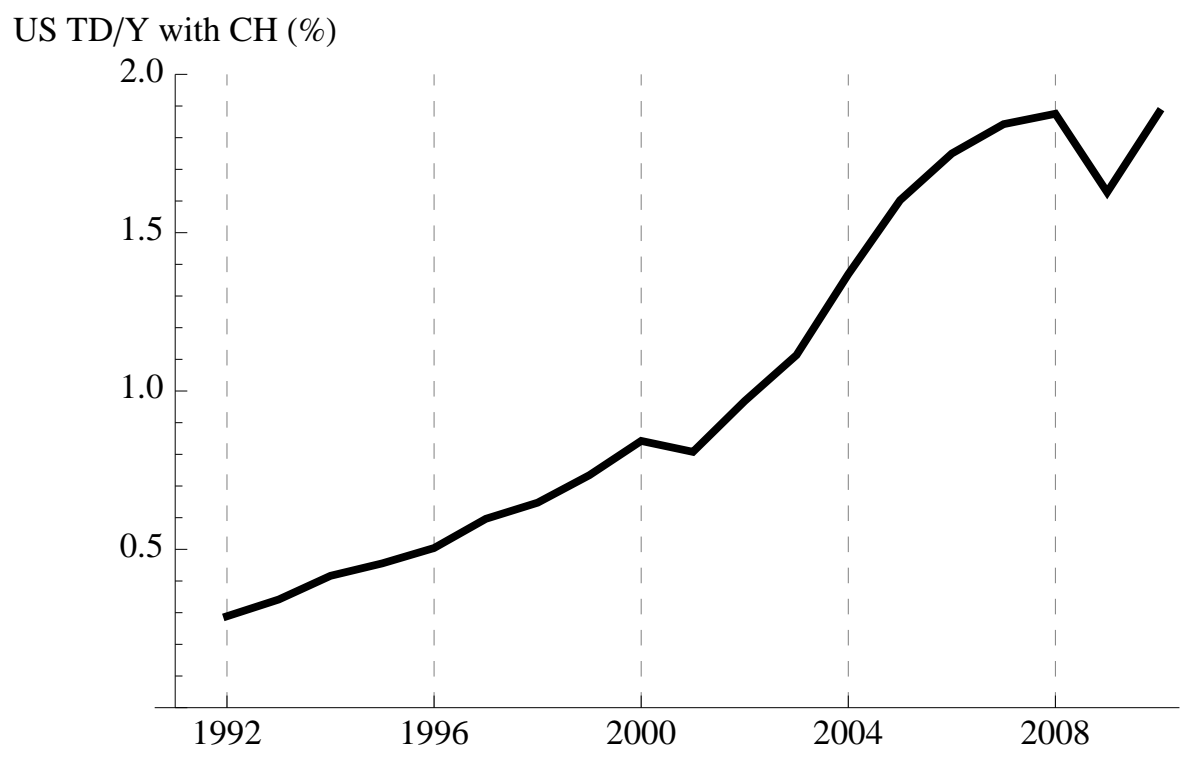

Figure 2: US trade deficit with China as \% of US GDP 1992-2010

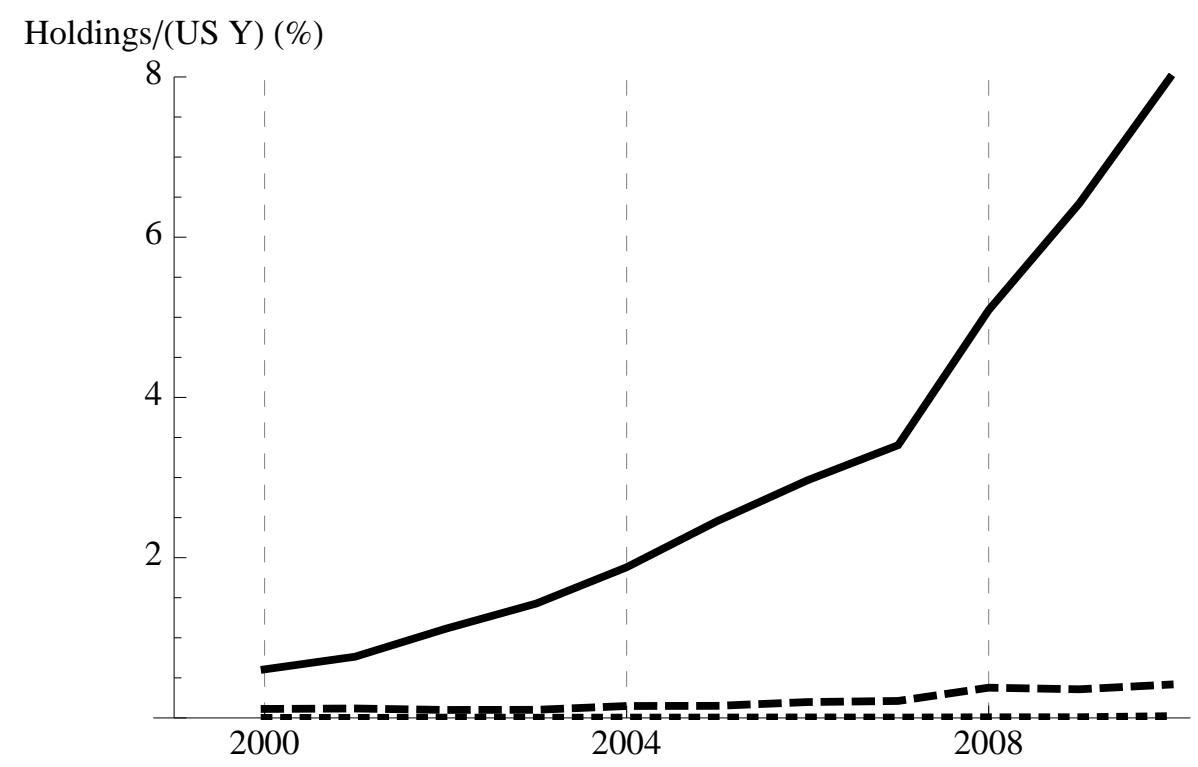

Figure 3: Cross-border asset holdings, 2000-2010. Chinese holdings of US Treasuries: solid; US FDI stock in China: dashed; Chinese FDI stock in US: dotted 


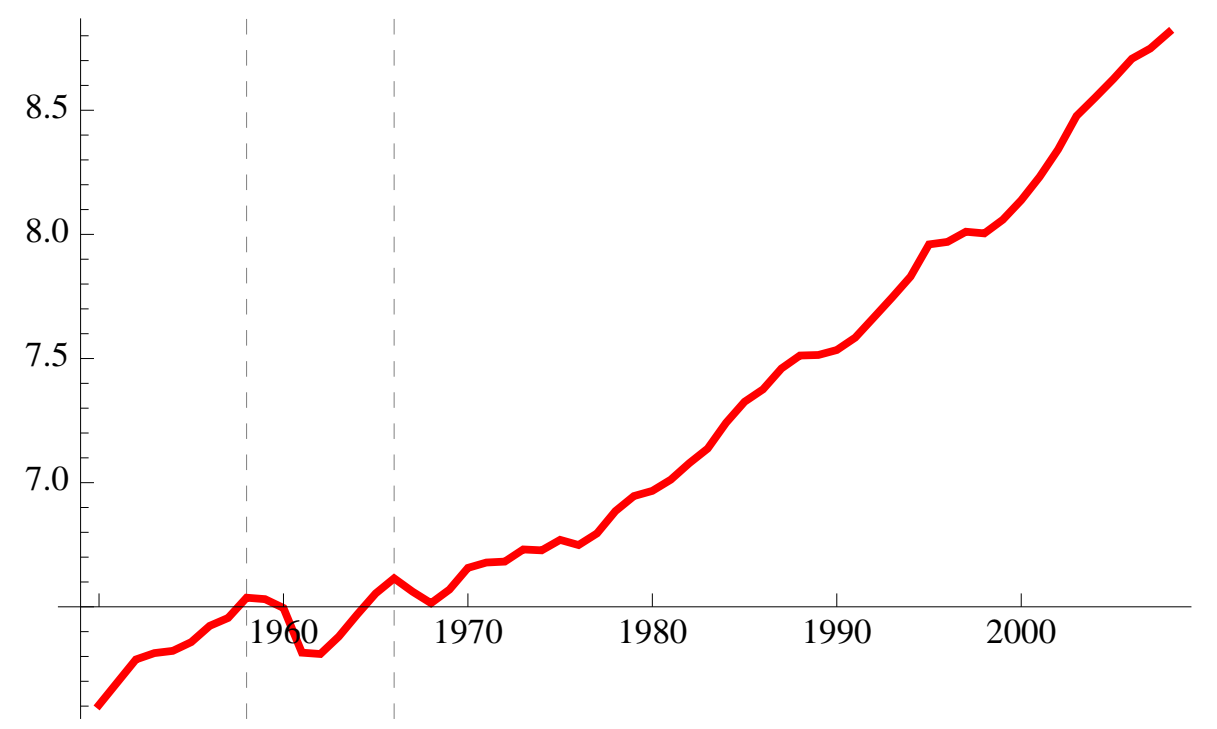

Figure 4: Logarithm of Chinese real per capital output, 1950-2008, with onset of disasters indicated

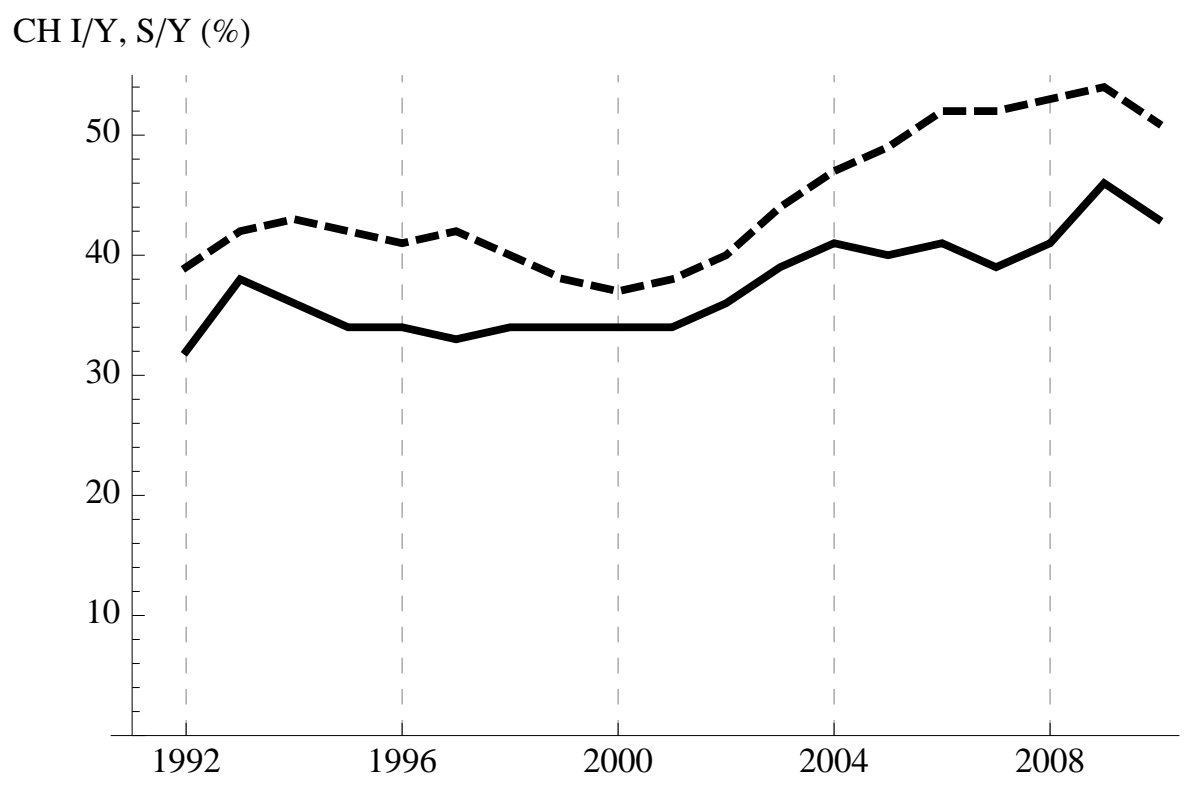

Figure 5: Chinese national investment (solid) and savings (dashed) as \% of Chinese GDP 1992-2010 


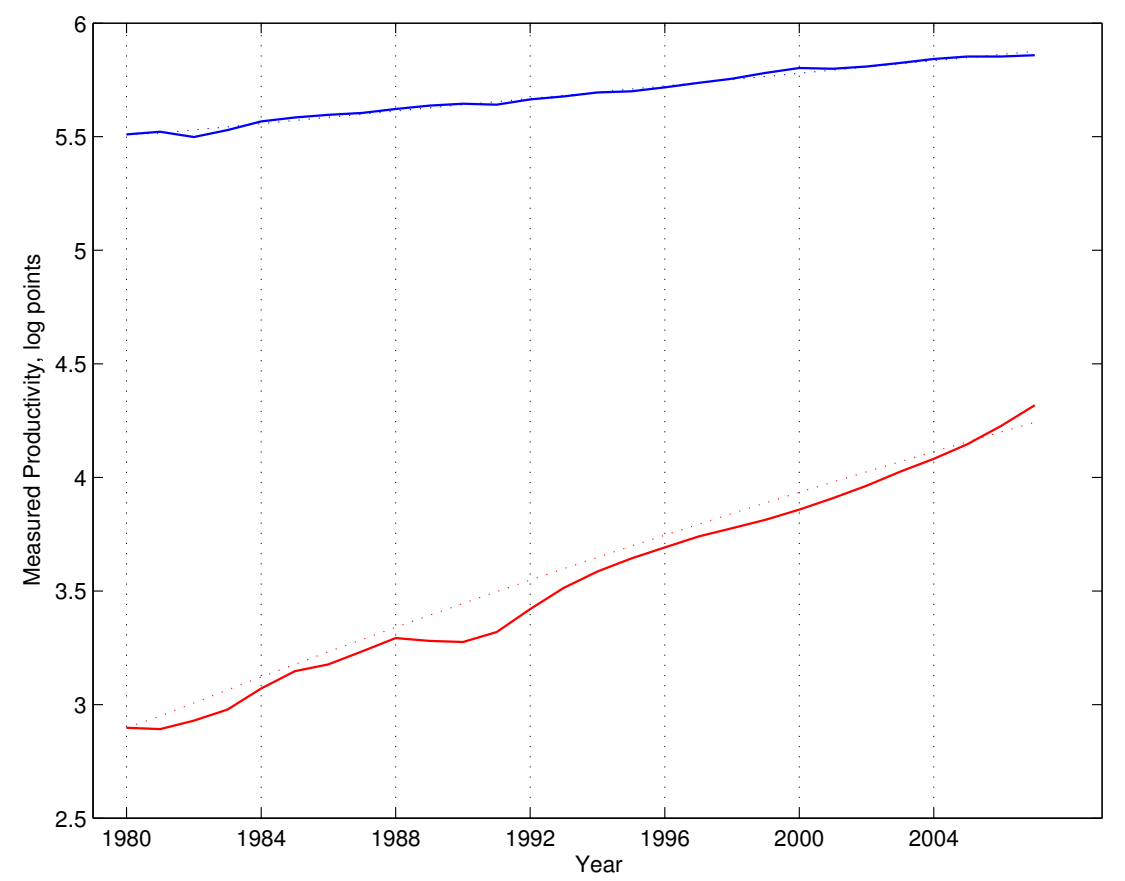

Figure 6: Logs of US (blue) and Chinese (red) productivity from 1980 to 2007, with global productivity frontier trend (dotted blue) and counterfactual Chinese productivity (dotted red)

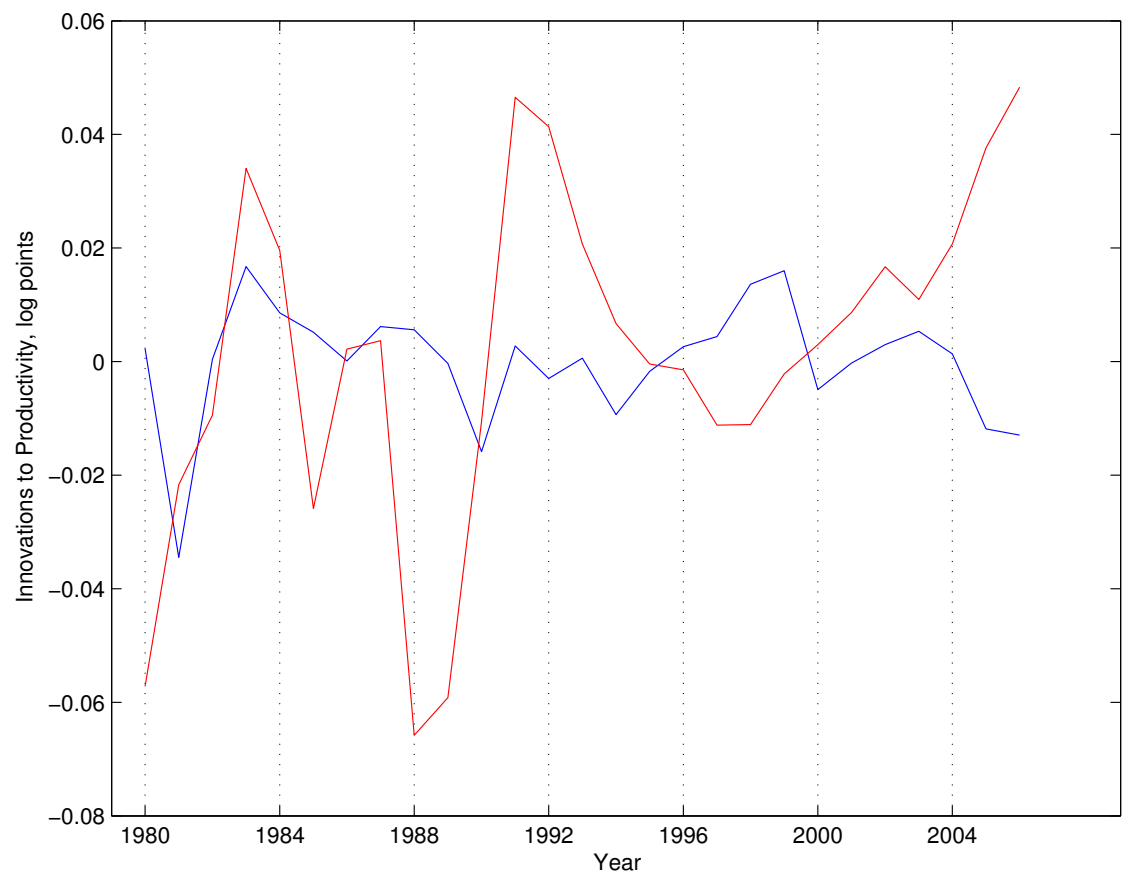

Figure 7: Estimated residuals $\left(\hat{\epsilon}_{t}, \hat{\epsilon}_{t}^{*}\right)$ of US (blue) and Chinese (red) productivity from 1980 to 2007 

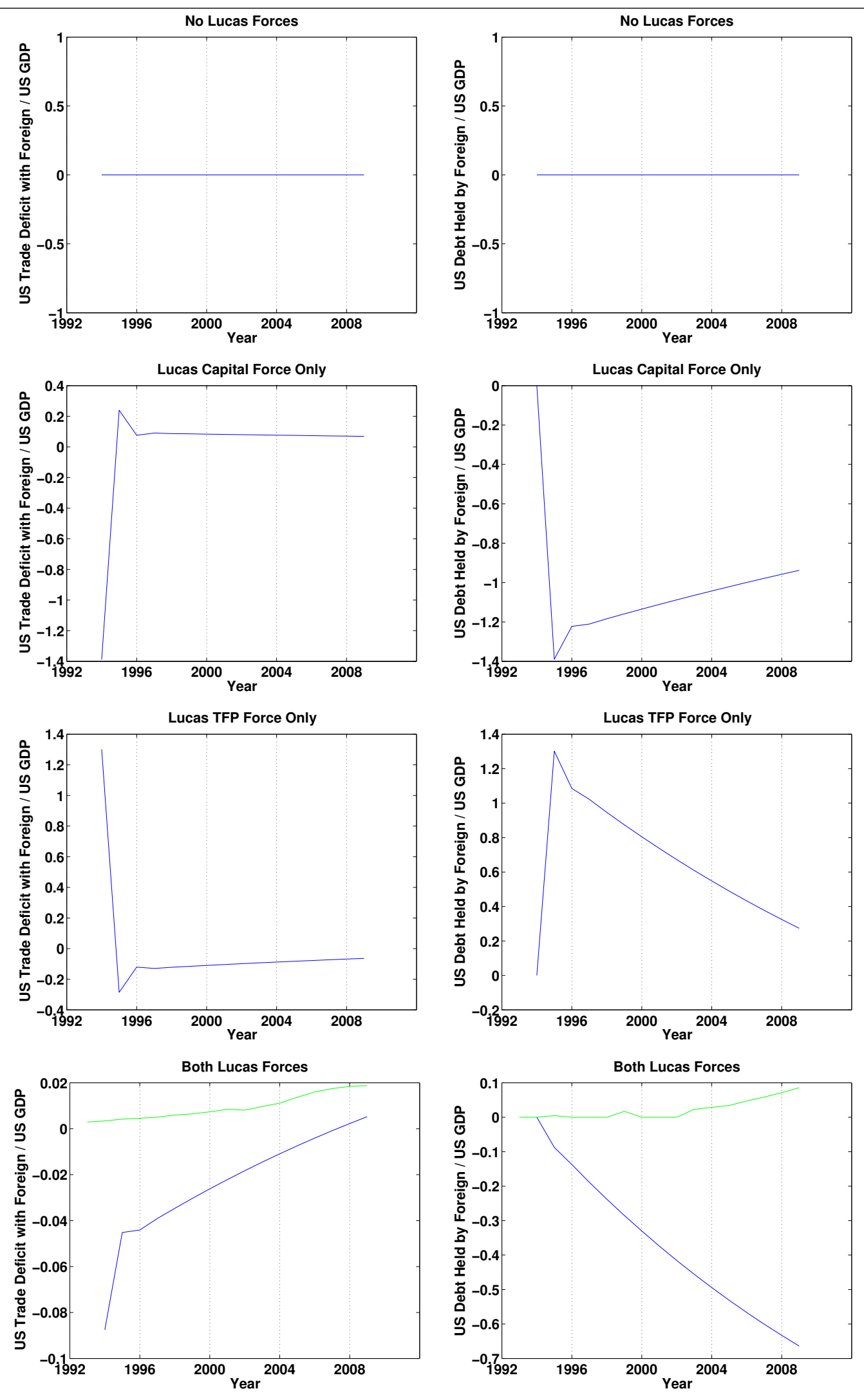

Table 2: Experiments: nonstochastic. Solid line: model-implied impulse response. Dashed line: data. 

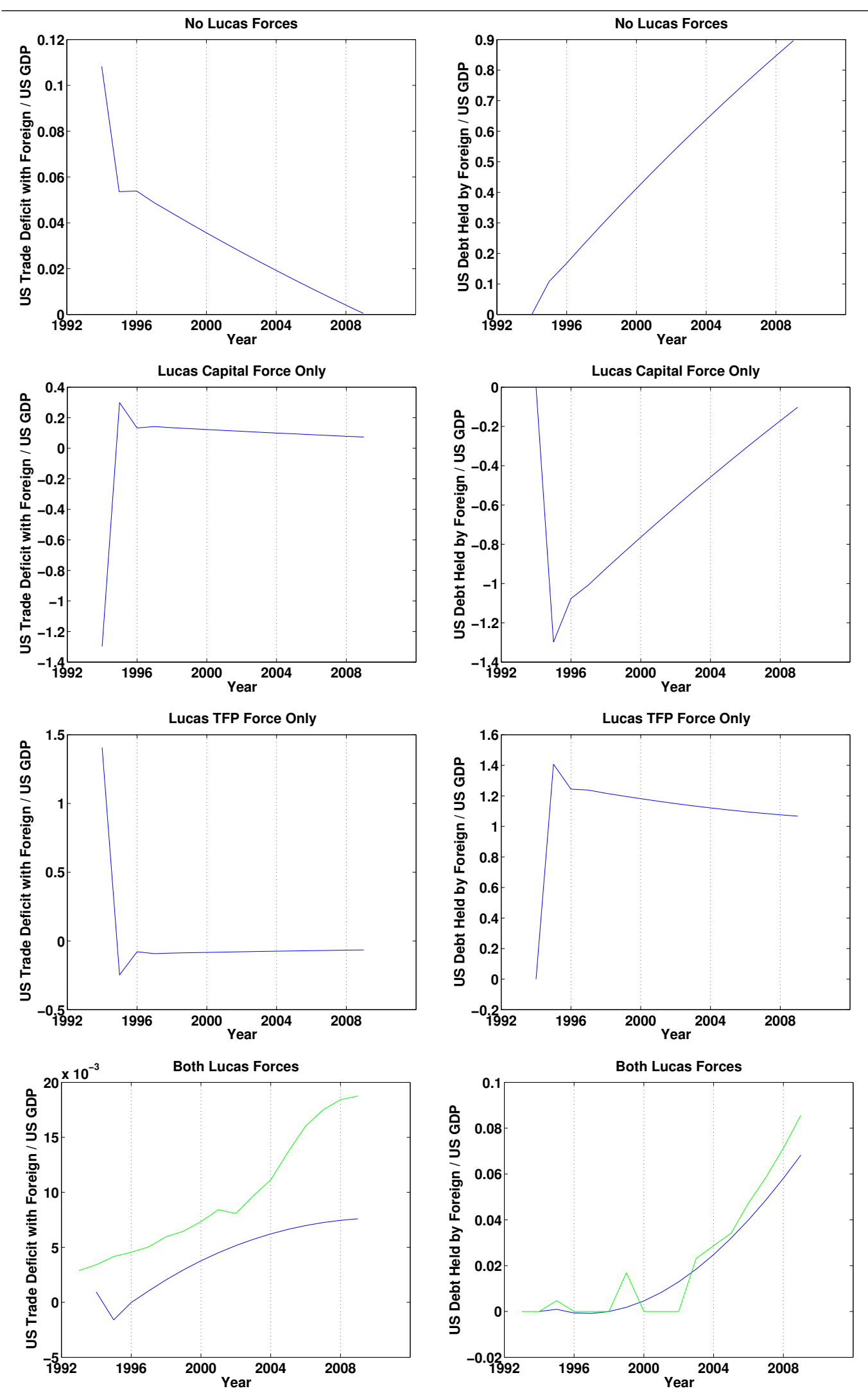

Table 3: Experiments: both noise and disasters. Solid line: model-implied impulse response. Dashed line: data. 

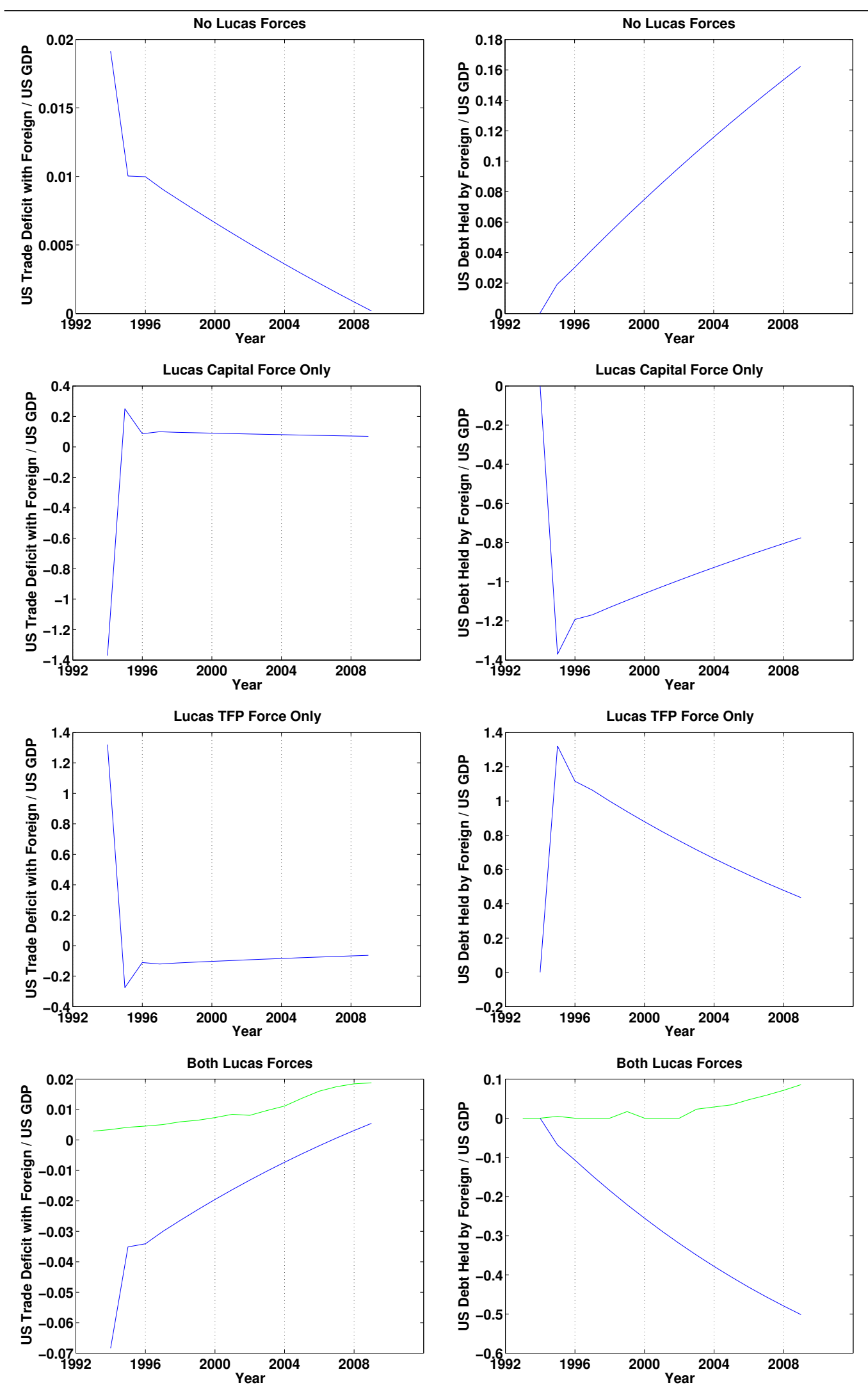

Table 4: Experiments: noise but no disasters. Solid line: model-implied impulse response. Dashed line: data. 

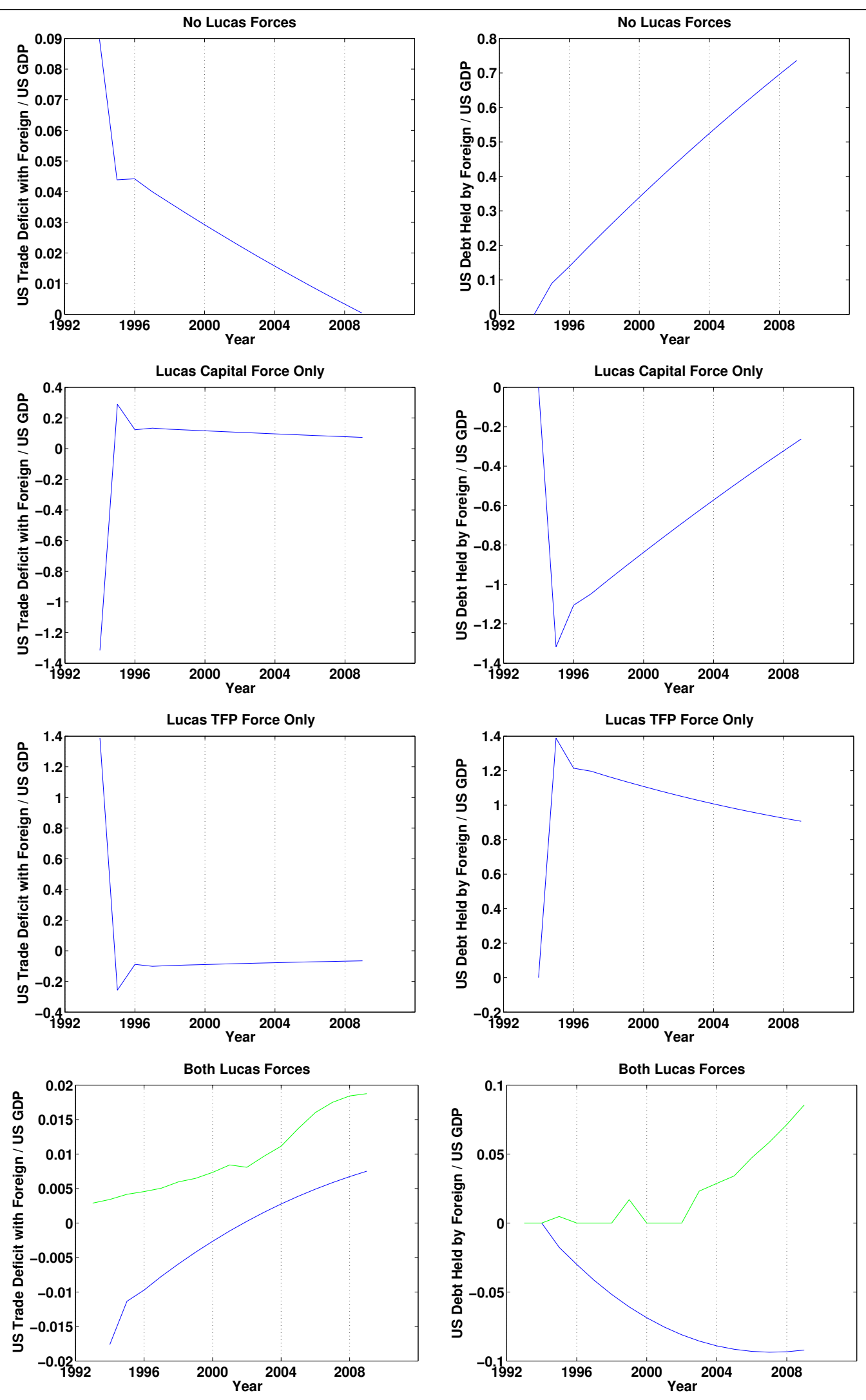

Table 5: Experiments: both noise and disasters, lower risk aversion. Solid line: modelimplied impulse response. Dashed line: data. 

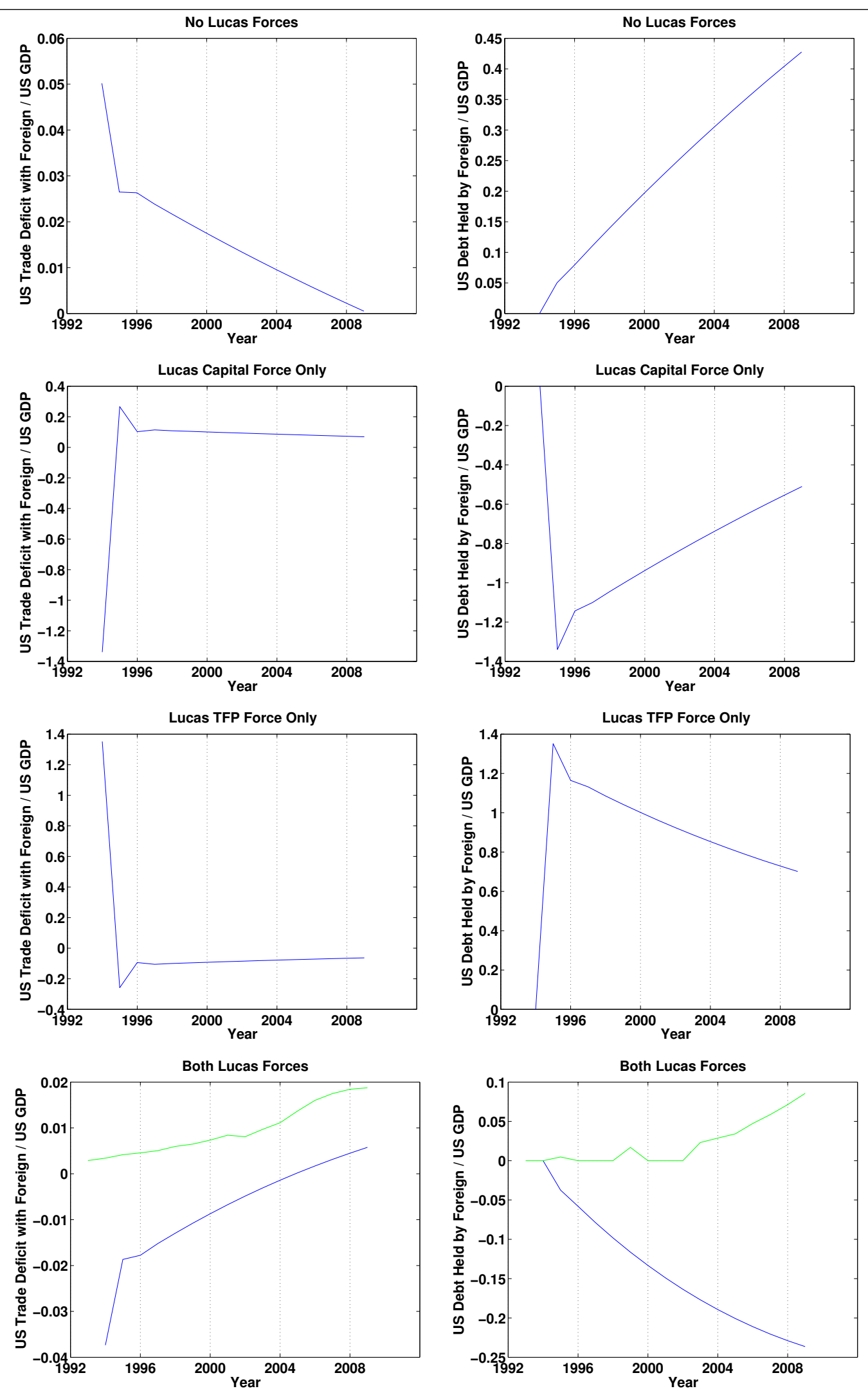

Table 6: Experiments: noise only, higher risk aversion. Solid line: model-implied impulse response. Dashed line: data. 

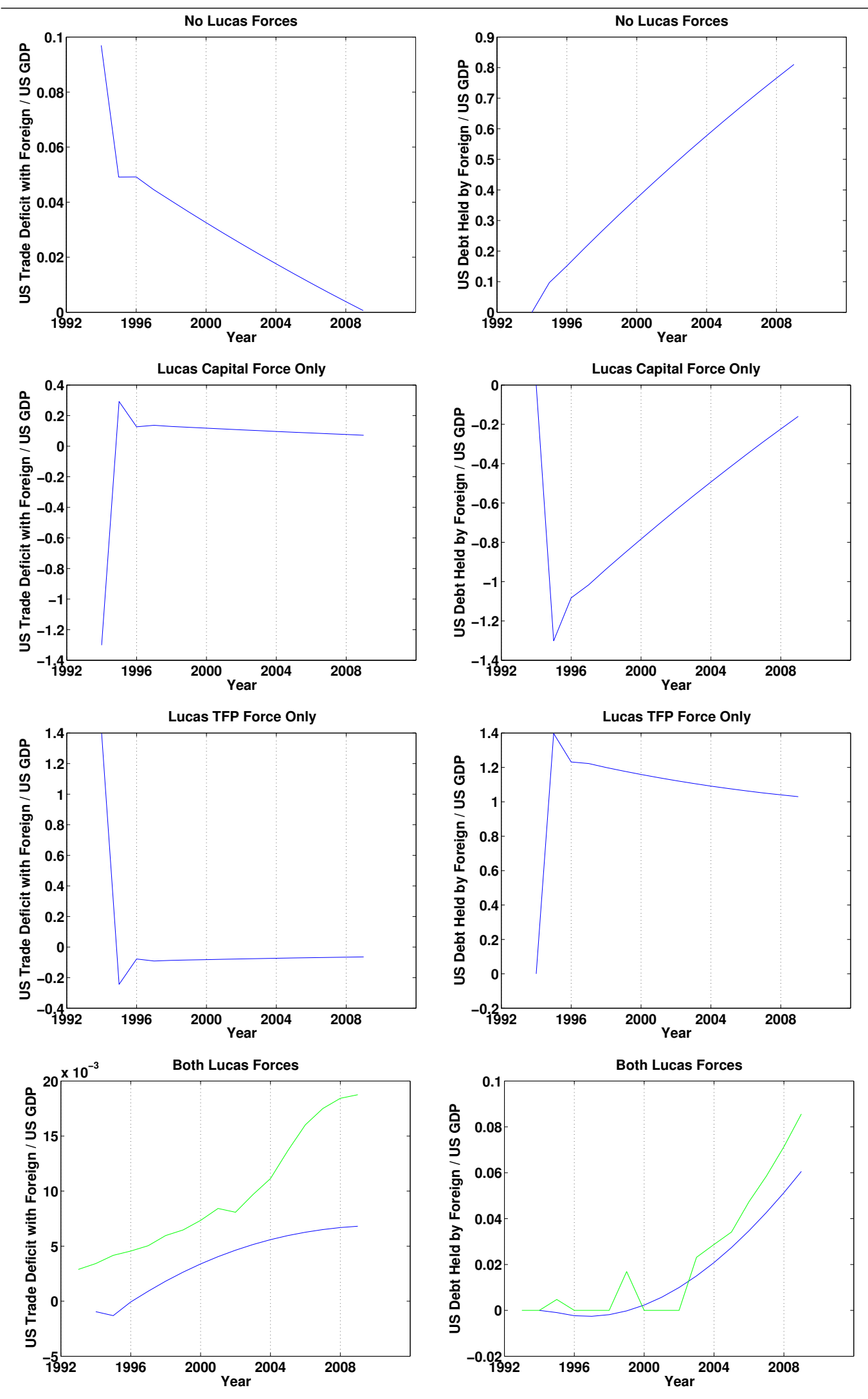

Table 7: Experiments: both noise and disasters, larger but rarer disasters. Solid line: modelimplied impulse response. Dashed line: data. 